\title{
Prevalence of intestinal parasitic infections among highland and lowland dwellers in Gamo area, South Ethiopia
}

Teklu Wegayehu ${ }^{1,2^{*}}$, Tsegaye Tsalla ${ }^{3}$, Belete Seifu ${ }^{1}$ and Takele Teklu ${ }^{2,4}$

\begin{abstract}
Background: Epidemiological information on the prevalence of intestinal parasitic infections in different regions is a prerequisite to develop appropriate control strategies. Therefore, this present study was conducted to assess the magnitude and pattern of intestinal parasitism in highland and lowland dwellers in Gamo area, South Ethiopia.

Methods: Community-based cross-sectional study was conducted between September 2010 and July 2011 at Lante, Kolla Shelle, Dorze and Geressie kebeles of Gamo Gofa Zone, South Ethiopia. The study sites and study participants were selected using multistage sampling method. Data were gathered through house-to-house survey. A total of 858 stool specimens were collected and processed using direct wet mount and formol-ether concentration techniques for the presence of parasite.
\end{abstract}

Results: Out of the total examined subjects, 342(39.9\%) were found positive for at least one intestinal parasite. The prevalence of Entamoeba histolytica/dispar was the highest 98(11.4\%), followed by Giardia lamblia 91(10.6\%), Ascaris lumbricoides 67(7.8\%), Strongyloides stercoralis 51(5.9\%), hookworm 42(4.9\%), Trichuris trichiura 24(2.8\%), Taenia species $18(2.1 \%)$, Hymenolepis nana 7(0.6\%) and Schistosoma mansoni 1(0.12\%). No statistically significant difference was observed in the prevalence of intestinal parasitic infections among lowland (37.9\%) and highland dwellers (42.3\%) $(P=0.185)$. The prevalence of intestinal parasitic infection was not significantly different among the study sites but it was relatively higher in Geressie (42.8\%) than other kebeles. Sex was not associated with parasitic infections ( $P=0.481$ ). No statistically significant difference of infection was observed among the age groups $(P=0.228)$ but it was higher in reproductive age group.

Conclusions: The high prevalence of intestinal parasitic infections among the lowland and highland dwellers in Gamo area indicated that parasitic infections are important public health problems. Thus, infection control measures and the development of awareness strategies to improve sanitation and health education should be considered.

Keywords: Control strategies, Intestinal parasites, Parasitism, Protozoan

\section{Background}

Intestinal parasitic infestation represents a large and serious medical and public health problem in developing countries. It is estimated that some 3.5 billion people are affected, and that 450 million are ill as a result of these infections, the majority being children [1]. Apart from causing morbidity

\footnotetext{
* Correspondence: tekluweg2007@yahoo.com

'Department of Biology, Arba Minch University, P. O. Box 21, Arba Minch, Ethiopia

${ }^{2} \mathrm{PhD}$ candidate in Tropical and Infectious Diseases, Aklilu Lemma Institute of Pathobiology, Addis Ababa University, Addis Ababa, Ethiopia

Full list of author information is available at the end of the article
}

and mortality, infection with intestinal parasites has known to cause iron deficiency anemia, growth retardation in children and other physical and mental health problems [2]. Furthermore, chronic intestinal parasitic infections have become the subject of speculation and investigation in relation to the spreading and severity of other infectious diseases of viral origin, tuberculosis and malaria [3-6].

Several factors like climatic conditions, poor sanitation, unsafe drinking water, and lack of toilet facilities are the main contributors to the high prevalence of intestinal parasites in the tropical and sub-tropical countries [7]. In

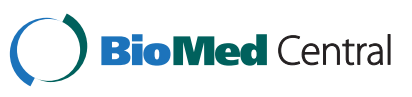


addition, intestinal parasitic agents increase in polluted environments such as refuse heaps, gutters and sewage units in and around human dwelling and living conditions of the people in crowded or unhealthy situations [8]. Hence, a better understanding of the above factors, as well as how social, cultural, behavioral and community awareness affect the epidemiology and control of intestinal parasites may help to design effective control strategies for these diseases $[9,10]$.

Intestinal parasites are widely distributed in Ethiopia largely due to the low level of environmental and personal hygiene, contamination of food and drinking water that results from improper disposal of human excreta $[11,12]$. In addition, lack of awareness of simple health promotion practices is also a contributing factor [13]. According to the Ethiopian Ministry of Health [14] more than half a million annual visits of the outpatient services of the health institutions are due to intestinal parasitic infections. However, this report may be an underestimate, because most of the health institutions lack appropriate diagnostic methods to detect low levels of parasite burden. In addition, some of the diagnostic methods for specific intestinal parasites, especially for the newly emerging opportunistic intestinal parasites, are not available to peripheral health institutions.

Previous studies gave due attention to the distributions of intestinal parasites in different altitudes, community groups such as school children or other groups confined to camps [15-18]. Hence, the pattern of intestinal parasitism in a community with diverse groups of people as a whole was not illustrated particularly in the study area. The purpose of this study was to assess the magnitude and patterns of intestinal parasitism in highland and lowland dwellers, Gamo area, South Ethiopia.

\section{Methods}

\section{Study area}

A community-based cross-sectional study was conducted between September 2010 and July 2011 in four selected areas of Gamo Gofa Zone administrative sub-division: Lante, Kolla Shelle, Dorze and Geressie kebeles. The zone is located at $505 \mathrm{kms}$ South of Addis Ababa and has a total area of 12, 581.4 square kms. The general elevation of the zone ranges from 600 to $3300 \mathrm{~m}$ above sea level. The highland and lowland areas of the zone are characterized by an average annual rain fall of $1166 \mathrm{~mm}$ and $900 \mathrm{~mm}$, respectively. The topography of the land is characterized by an undulating feature that makes the existence of different climatic zones in the area possible.

Two of the study 'kebeles' (these are the smallest officially acknowledged administrative vicinities in the zone): Dorze and Geressie kebeles are positioned on the highland areas where as Lante and Kolla Shelle kebeles are situated on lowland settings of the zone. They are located a short distance from the zonal administrative center, Arba Minch. Dorze and Lante are located at $30 \mathrm{kms}$ and $22 \mathrm{kms}$ to the north, where as Geressie and Kolla Shelle are located at $56 \mathrm{kms}$ and $28.6 \mathrm{kms}$ to the south of Arba Minch, respectively. In all study kebeles healthcare is provided by health centers and private clinics which are staffed by few health officers, nurses and laboratory technicians. Though it is irregular and non-continuous, the control measures for intestinal parasites include health education, deworming of under five year children and treatment of drinking water.

\section{Sample size and sampling techniques}

The sample size was determined using the single proportion population formula. It was calculated based on a prevalence of $83 \%$ [19] with a margin of error of 0.05 and a confidence level of $95 \%$. The design effect was calculated by taking the intraclass correlation for the statistic (i.e.1\%) in parasitic infection in highland and lowland areas of Ethiopia. A design effect of 4 was used to allow for multistage sampling. The calculated study sample size was 867 . The study sites were divided into two regions based on altitude and from each altitude two kebeles were randomly selected. The households were selected using systematic sampling method and the study individuals were chosen using a simple random sampling method. The calculated sample size was divided to each kebele based on population size. As a result, 464 (192 from Lante and 272 from Kolla Shelle) samples were obtained from lowland and 403 (124 from Dorze and 279 from Geressie) samples were obtained from highland settings.

\section{Stool collection and processing}

About $2 \mathrm{~g}$ of fresh fecal samples were collected from each consenting study subject and placed in separate labeled clean plastic stool containers. At the time of collection, date of sampling, the name of the participant, age, sex and consistency of the stool (formed, soft, semisoft and watery) were recorded for each subject on a recording format. A portion of stool was examined at field by direct wet mount with saline $(0.85 \%$ sodium chloride solution) to observe motile intestinal parasites and trophozoites under light microscope at $100 \times$ and $400 \times$ magnifications. The remaining part was preserved with $10 \%$ formalin in the ratio of $1 \mathrm{~g}$ of stool to $3 \mathrm{ml}$ of formalin for later examination at Arba Minch University. Lugol's iodine staining technique was also done to observe cysts of the intestinal protozoan parasites. A portion of preserved stool sample was processed by formol-ether concentration method as described by Ritchie [20], with some modification. In brief the stool sample was sieved with cotton gauze and transferred to $15 \mathrm{ml}$ centrifuge tube. Then $8 \mathrm{ml}$ of $10 \%$ formalin and $3 \mathrm{ml}$ of diethyl ether 
was added and centrifuged for $2 \mathrm{~min}$ at $2000 \mathrm{rpm}$. The supernatant was discarded and the residues were transferred to microscopic slides and observed under light microscope at $100 \times$ and $400 \times$ magnifications for the presence of cysts and ova of the parasites. The presence of parasites was confirmed when observed by any of the methods above.

\section{Quality control}

Before starting the actual work, quality of reagents and instruments were checked by experienced laboratory technologist. The specimens were also checked for serial number, quality and procedures of collection. To eliminate observer bias, each stool sample was examined by two laboratory technicians. The technicians were not informed about the health and other status of the study participants. In cases where the results were discordant, a third senior reader was used. The result of the third expert reader was considered the final result.

\section{Data analysis}

Statistical analysis was performed with SPSS software version 16 . Chi-square $(\chi 2)$ was used to verify possible association between infection and exposure to different factors. Probability values were considered to be statistically significant when the calculated P-value was equal to or less than 0.05 .

\section{Ethical clearance}

The study was reviewed and approved by ethical committee of Arba Minch University. The ethical considerations were addressed by treating positive individuals using standard drugs under the supervision of a local nurse. The objective of the study was explained to kebele leaders and dwellers; and written consent was sought from parents or guardians of the selected children during stool sample collection.

\section{Results}

A total of 867 study participants were selected for investigation. However, 10(1.2\%) were excluded because of inability to provide specimen. For this reason a total of 858 individuals were included in the study (Table 1). Three hundred forty two of the study individuals were found to have single or multiple intestinal parasitic infections, which make the overall prevalence $39.9 \%$. Of the entire positive samples for the parasite, 188 were female participants and 154 were male participants with female to male ratio of 1:0.8 (Table 1). The mean age of the participants was $25 \pm 19$.

Different types of parasites including protozoans, trematode, cestodes and nematodes were detected from the stool samples of study participants. Prevalence of Entamoeba histolytica/dispar (E. histolytica/dispar) was the highest 98
Table 1 Frequency distribution of sex, age group and altitude of the study subjects in Gamo area

\begin{tabular}{|c|c|c|c|c|c|}
\hline \multirow[t]{2}{*}{ Characteristics } & \multicolumn{3}{|c|}{ Frequencies } & \multirow{2}{*}{$x^{2}$} & \multirow{2}{*}{$\begin{array}{c}P \\
\text { value }\end{array}$} \\
\hline & Positive (\%) & Negative & Total & & \\
\hline \multicolumn{6}{|l|}{ Sex } \\
\hline Male & 154 (38.6) & 245 & 399 & & \\
\hline Female & $188(41.0)$ & 271 & 459 & 0.49 & 0.481 \\
\hline Total & $342(39.9)$ & 516 & 858 & & \\
\hline \multicolumn{6}{|l|}{ Age group } \\
\hline$<4$ & $20(29.4)$ & 48 & 68 & & \\
\hline $5-14$ & 91 (38.6) & 145 & 236 & & \\
\hline $15-44$ & $179(42.3)$ & 244 & 423 & 4.33 & 0.228 \\
\hline$>44$ & $52(39.7)$ & 79 & 131 & & \\
\hline Total & 342 (39.9) & 516 & 858 & & \\
\hline \multicolumn{6}{|l|}{ Altitude } \\
\hline Lowland* & $174(37.9)$ & 285 & 459 & & \\
\hline Highland** & $169(42.3)$ & 230 & 399 & 1.75 & 0.185 \\
\hline Total & 342 (39.9) & 516 & 858 & & \\
\hline
\end{tabular}

Key: * Lante and Kolla Shelle.

** Dorze and Gereessie.

(11.4\%), followed by Giardia lamblia (G. lamblia) 91 (10.6\%), Ascaris lumbricoides (A. lumbricoides) 67(7.8\%), Strongyloides stercoralis (S. stercoralis) 51(5.9\%), hookworm 42(4.9\%), Trichuris trichiura (T. trichiura) 24(2.8\%), Taenia species (Taenia spp.) 18(2.1\%), Hymenolepis nana (H. nana) 7(0.6\%) and Schistosoma mansoni (S. mansoni) $1(0.12 \%)$, in that order. The majorities of the positive cases were single infections (83.9\%) and double infections (15.5\%). Of the triple infected persons, one was coinfected with E. histolytica/dispar, G. lamblia and Taenia spp. and the other with E. histolytica/dispar, S. stercoralis and hookworm (Figure 1).

The prevalence of infection with different intestinal helminths and protozoan parasites for lowland (Lante and Kolla Shelle) and highland (Dorze and Gressie) is shown in Table 2. Out of 459 stool samples collected from lowland area, 174(37.9\%) were positive for at least one parasite. Similarly, of the 399 stool samples collected from highland area, 169(42.3\%) were positive for at least one parasite. No statistically significant difference was observed $(P=0.185)$ between presence of intestinal parasites and altitude (Tables 1 and 2). However, G. lamblia $(\mathrm{P}<0.001)$ and hookworm $(P=0.002)$ were significantly more prevalent in lowland areas whereas $A$. lumbricoides $(\mathrm{P}<0.001)$ and T. trichiura $(\mathrm{P}<0.001)$ were significantly more prevalent in highland areas, but $S$. stercoralis was exclusive to lowland areas (Table 2).

As observed in Table 2, of 190 and 269 stool samples collected from Lante and Kolla Shelle, 66(34.7\%) and 108(40.1\%) were found positive for at least one parasite, respectively. Similarly, out of 123 and 276 fecal samples 


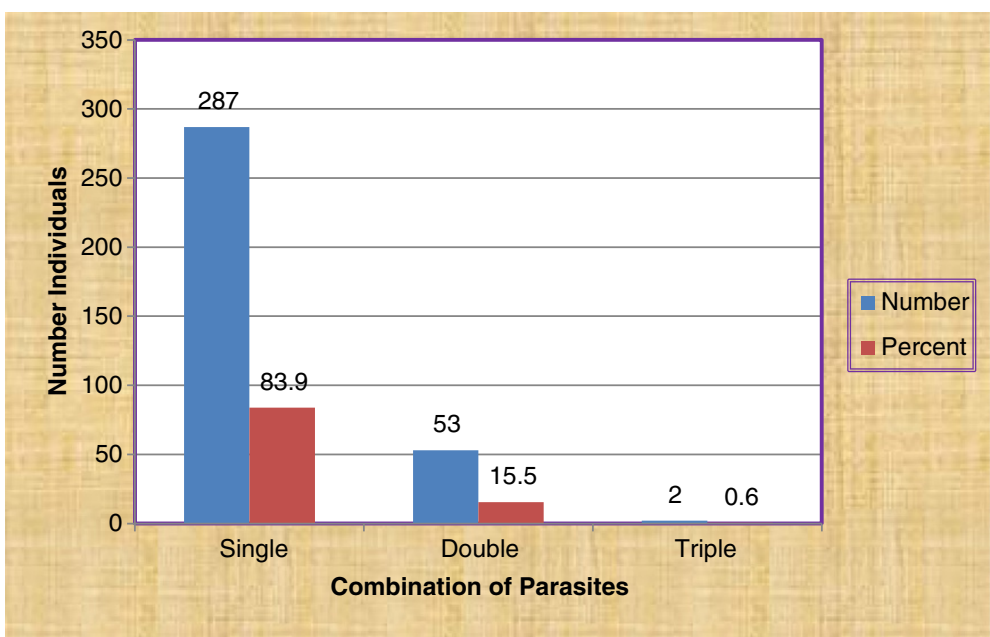

Figure 1 Single and mixed infections among residents of Gamo area, Gamo Gofa Zone, South Ethiopia.

collected from Dorze and Geressie sites, 50(40.7\%) and $118(42.8 \%)$ were infected with one or more intestinal parasites. The overall difference in parasite prevalence was no statistically significant among the study sites, $(\mathrm{P}=0.38)$. However, E. histolytica/dispar prevalence was significantly higher in Geressie $(\mathrm{P}<0.001)$ than other study areas. A. lumbricoides and T. trichiura were significantly higher in Dorze $(\mathrm{P}<0.005)$ and $S$. mansoni was detected in Lante alone.

The distribution of infection among female and male participants is shown in Table 3. Female participants showed the highest infection rate (41.0\%), followed closely by male participants (38.6\%) (Table 1$)$. The calculated P-value (0.48) indicates that the difference in the prevalence of intestinal parasites between female and male participants was statistically not significant.
However, A. lumbricoides infection was significantly higher $(\mathrm{P}=0.004)$ among female participants than male participants (Table 3$)$.

To see variations in age group, the study population was divided into 4 age groups: birth to 4 years, 5 to 14 years, 15-44 years, and over 44 years. The distribution of infection among study subjects in the different age groups is shown in Table 4. The overall infection rate was highest among the 15-44 years age group (42.3\%) followed by above 44 years age group (39.7\%). Only $29.4 \%$ of children from birth to 4 years age group were infected. The difference in the prevalence of intestinal parasites was insignificant $(\mathrm{P}=0.228)$ among the age groups (Table 1). Each parasite was also not associated with the age of the participant $(\mathrm{P}>0.005)$ except T. trichiura which shown significantly high $(\mathrm{P}=0.007)$

Table 2 Prevalence of intestinal parasites among study subjects in lowland and highland dwellers in Gamo area

\begin{tabular}{|c|c|c|c|c|c|c|c|c|c|}
\hline \multirow{4}{*}{ Parasites } & \multicolumn{6}{|c|}{ Study sites } & \multirow{4}{*}{$\begin{array}{c}\text { Total } \\
(\mathrm{n}= \\
858) \\
\text { No }(\%)\end{array}$} & \multirow{4}{*}{$x^{2}$} & \multirow{4}{*}{ P-value } \\
\hline & \multicolumn{3}{|c|}{ Lowland } & \multicolumn{3}{|c|}{ Highland } & & & \\
\hline & $\begin{array}{c}\text { Lante } \\
(n=190)\end{array}$ & $\begin{array}{c}\text { Shelle } \\
(n=269)\end{array}$ & $\begin{array}{c}\text { Total } \\
(n=459)\end{array}$ & $\begin{array}{c}\text { Dorze } \\
(n=123)\end{array}$ & Geressie $(n=276)$ & $\begin{array}{c}\text { Total } \\
(\mathrm{n}=399)\end{array}$ & & & \\
\hline & No (\%) & No (\%) & No (\%) & No (\%) & No (\%) & No (\%) & & & \\
\hline E. histolytica/dispar & $9(4.7)$ & $19(7.1)$ & $28(6.1)$ & $1(0.8)$ & $69(25.0)$ & $70(17.5)$ & $98(11.4)$ & 27.63 & $<0.001^{*}$ \\
\hline G. lamblia & $28(14.7)$ & $46(17.1)$ & $74(16.1)$ & $2(1.6)$ & $15(5.4)$ & $17(4.3)$ & 91 (10.6) & 31.67 & $<0.001^{*}$ \\
\hline A. lumbricoides & $2(1.1)$ & $1(0.4)$ & $3(0.6)$ & 27 (21.9) & $37(13.4)$ & $64(16.0)$ & $67(7.8)$ & 70.19 & $<0.001 *$ \\
\hline H. nana & $2(1.1)$ & $3(1.1)$ & $5(1.1)$ & $1(0.8)$ & $1(0.4)$ & $2(0.5)$ & $7(0.6)$ & 0.91 & 0.344 \\
\hline Hookworm & $14(7.4)$ & $19(7.0)$ & $33(7.2)$ & $1(0.8)$ & $8(2.9)$ & $9(2.2)$ & $42(4.9)$ & 9.83 & $0.002^{*}$ \\
\hline S. mansoni & $1(0.5)$ & - & $1(0.2)$ & - & -— & -—- & $1(0.12)$ & - & - \\
\hline S. stercoralis & $17(8.9)$ & $34(12.6)$ & $51(11.1)$ & - - & -— & -—— & $51(5.9)$ & - & - \\
\hline Taenia spp & $4(2.1)$ & $9(3.3)$ & $13(2.8)$ & $4(3.3)$ & $1(0.4)$ & $5(1.2)$ & $18(2.1)$ & 2.59 & 0.107 \\
\hline T. trichiura & - & $1(0.4)$ & $1(0.2)$ & $21(17.0)$ & $2(0.7)$ & $23(5.8)$ & $24(2.8)$ & 24.21 & $<0.001^{*}$ \\
\hline
\end{tabular}

Key: $X^{2}$ and $P$-value values represent lowland and highland comparison.

* Represent statistically significant difference $(P<0.05)$. 
Table 3 Sex related prevalence of intestinal parasites among study subjects in Gamo area

\begin{tabular}{lccccc}
\hline \multirow{1}{*}{$\begin{array}{c}\text { Parasites } \\
\text { detected }\end{array}$} & $\begin{array}{c}\text { Male (n= 399) } \\
\text { No (\%) }\end{array}$ & $\begin{array}{c}\text { Female (n= 459) } \\
\text { No (\%) }\end{array}$ & $x^{2}$ & $\begin{array}{c}\text { P- } \\
\text { value }\end{array}$ \\
\cline { 2 - 4 } E. histolytica/dispar & $37(9.3)$ & $61(13.3)$ & 3.40 & 0.065 \\
G. lamblia & $43(10.8)$ & $48(10.5)$ & 0.02 & 0.880 \\
A. lumbricoides & $20(5.0)$ & $47(10.2)$ & 8.10 & $0.004^{*}$ \\
H. nana & $4(1.0)$ & $3(0.7)$ & 0.32 & 0.571 \\
Hookworm & $25(6.3)$ & $17(3.7)$ & 3.01 & 0.083 \\
S. mansoni & $1(0.3)$ & -- & - & - \\
S. stercoralis & $28(7.0)$ & $23(5.0)$ & 1.54 & 0.215 \\
Taenia spp & $8(2.0)$ & $10(2.2)$ & 3.62 & 0.057 \\
T. trichiura & $10(2.5)$ & $14(3.1)$ & 0.23 & 0.630 \\
\hline
\end{tabular}

Key: * Represent statistically significant difference $(P<0.05)$.

prevalence among the age group of 5-14 years (Table 4).

\section{Discussion}

Primary objectives of epidemiological studies on the prevalence of infection of intestinal parasites in different regions/localities are to identify high-risk communities and formulate appropriate intervention. In line with this view, the present study attempted to assess the prevalence of different intestinal parasitic infections in highland and lowland dwellers in Gamo area, Gamo Gofa Zone and then recommend appropriate intervention.

The results of the study showed the occurrence of several intestinal parasites of public health importance among inhabitants in four kebeles found in Gamo area of Gamo Gofa Zone, South Nations. The overall prevalence of $39.9 \%$ with one or more intestinal parasites found in this study was much lower than what was reported
(82.8\%) from residents of four villages in southwestern Ethiopia by Yeneneh [21]; (83.8\%) from school-children around Lake Langano by Legesse and Erko [22] and from that of Mengistu and collegues [19] (83\%) from urban dwellers in southwest Ethiopia. However, the prevalence in our study was slightly higher compared to other community-based studies conducted in Saudi Arabia by Al-Shammari et al. [23] showing an overall prevalence of $32.2 \%$. The possible explanations for the discrepancy between the present and previous study finding might be the result of variation in sampling techniques used, the difference in the quality of drinking water source, and variation in the environmental condition of the different study localities.

The prevalence of E. histolytica/dispar and G. lamblia infection in this study was $11.4 \%$ and $10.6 \%$, respectively. These are within the range of the nation-wide prevalence rate for amoebiasis and giardiasis [24]. However, the present finding was relatively higher than that reported from urban dwellers in southwest Ethiopia, where Mengistu et al. [19] recorded 3.1\% and 3.6\% for amoebiasis and giardiasis, respectively [19]. The prevalence of giardiasis was also higher than that of Birrie and Erko report of 3.1\% among non-school children [25]. Giardia cysts have been isolated from water supplies in different parts of the world [26,27]. Epidemic giardiasis may be related to drinking water [28]. The present study was also conducted in a rural area that may share the mentioned risk factors.

The level of ascariasis observed in this study (7.8\%) of fecal samples was far lower than that reported from urban dwellers in Jimma, where Mengistu et al. [19] recorded $41.0 \%$ prevalence. The prevalence of hookworm infection was $42(4.9 \%)$. The rate is lower than the previous community based study in Jimma, where Mengistu and colleagues recorded $17.5 \%$ prevalence

Table 4 Age related prevalence of intestinal parasites among study subjects in Gamo area

\begin{tabular}{|c|c|c|c|c|c|c|}
\hline \multirow{3}{*}{$\begin{array}{l}\text { Parasites } \\
\text { detected }\end{array}$} & \multicolumn{4}{|c|}{ Age Group } & \multirow{3}{*}{$x^{2}$} & \multirow{3}{*}{ P-value } \\
\hline & $<4(n=68)$ & $5-14(n=236)$ & $15-44(n=423)$ & $>44(n=131)$ & & \\
\hline & No (\%) & No (\%) & No (\%) & No (\%) & & \\
\hline E. histolytica/dispar & $9(13.2)$ & $21(8.9)$ & $54(12.8)$ & $54(12.8)$ & 2.56 & 0.462 \\
\hline G. lamblia & $10(14.7)$ & $22(9.3)$ & $22(9.3)$ & $15(11.5)$ & 1.73 & 0.630 \\
\hline A. lumbricoides & $2(2.9)$ & $22(9.3)$ & $29(6.9)$ & $14(10.7)$ & 5.03 & 0.170 \\
\hline H. nana & -— & $4(1.7)$ & $3(0.7)$ & - & & -— \\
\hline Hookworm & -—- & $10(4.2)$ & $24(5.7)$ & $8(6.1)$ & 4.68 & 0.197 \\
\hline S. mansoni & - & - & $1(0.2)$ & - - - & & -—- \\
\hline S. stercoralis & $1(1.5)$ & $13(5.5)$ & $26(6.1)$ & $11(8.4)$ & 3.96 & 0.266 \\
\hline Taenia spp & -—- & -—- & $16(3.9)$ & $2(1.5)$ & & -— \\
\hline T. trichiura & $1(1.5)$ & $14(5.9)$ & $6(1.4)$ & $3(2.3)$ & 12.05 & $0.007^{*}$ \\
\hline
\end{tabular}

Key: $<4$ years $=$ Preschool children, $5-14$ years $=$ School children, $15-44$ years $=$ Reproductive age, $>44$ years $=$ elder .

* Represent statistically significant difference $(P<0.05)$. 
[19]. However, the present findings on prevalence of S. stercoralis, $H$. nana, and Taenia spp. was not much different from the findings of previous studies reported by Woldemichael et al., McConnel and Armstrong [18,24].

Although significant difference was not observed, the prevalence of intestinal parasites infections was slightly lower among lowland dwellers (37.9\%) than highland dwellers (42.3\%). The existence of relatively low prevalence of human intestinal parasites in lowlands is due to low prevalence of $A$. lumbricoides and T. trichiura. A nation-wide study conducted on ascariasis in Ethiopia has indicated a low prevalence of ascariasis in the low and dry areas of the country [29]. In agreement to this report, the present study showed relatively low prevalence of ascariasis $(0.7 \%)$ and trichuriasis $(0.2 \%)$ among lowland dwellers. This might be because of proper toilet facilities, apposite hand washing habit and better awareness about health in lowland dwellers than highland dwellers in our study area.

Though the reason for high prevalence of G. lamblia in lowland area is unclear, the high prevalence of hookworm infection might be contributed to low shoe wearing habit during irrigation. According to the geo climatic type of area, significant highest prevalence of $S$. stercoralis infection was found in lowland. The explanation of this is that prevalence of $S$. stercoralis infection is parallel with hookworm infection [30]. This may lead us to a conclusion that geo climatic factors, such as soil textures, farming ecosystem, temperature, humidity and rainfall essentially influence the infection of S. stercoralis as the lowlands are located near Lake Abaya.

From the four study sites, S. mansoni was reported only from Lante kebele. However, the prevalence of S. mansoni (0.12) was much lower as compared to $14.8 \%$ reported by Mengistu et al. [19]. Although this study did not evaluate the migratory history of the study participants, the existence of such low level infection rate may imply the relocation of infected individual from endemic foci. Nevertheless, the presence of schistosome-infected dweller in Lante kebele represents a risk for the introduction of a new transmission focus where the snail hosts might be available. Hence, extensive study on the transmission foci in the area is recommended to take timely intervention.

Variations that might have occurred due to gender and age group differences were also examined in this current study. Variation of results due to gender differences was not observed in the study. The result was similar to a study conducted in the central part of Turkey [31]. But A. lumbricoides infection was significantly higher among female participants than male participants in this study. Though significant difference among age groups was not observed in the current study, the prevalence of infection was higher in reproductive age group. This might be due to the fact that this is the age group of working people who are engaged in agriculture and most likely exposed to infection through contaminated soil, water and food. The rate of infection by Taenia spp. was also higher in 15-44 and > 44 age groups. This could be due to the fact that as the child grows older the habit of feeding beef increases.

Multiple infections occurred in 55 individuals making $6.4 \%$ of the total examined subjects and $16.1 \%$ of those who had intestinal parasites. The level of double infections with intestinal parasites determined in the present study (6.2\%) was much lower than what was reported from southwest Ethiopia portraying a double infection of $35.8 \%$ among urban communities [19]. The possible difference in the socio-demographic condition of the study population and the environmental condition might explain the observed difference in double infection in the two study localities.

This study did not assess opportunistic intestinal parasitic infections due to lack of laboratory facilities in our department. Although important risk factors such as age, sex and altitude were considered, some risk factors were not evaluated in the current study. Apart from these limitations our study has the following strengths. It is the first of its kind in the area i.e. pattern of intestinal parasitism was not studied earlier than this current study in the study area. Moreover, all the participants from each kebele were sampled at one specific time in the sampling period to avoid seasonal biases. In addition, the sample was collected from the entire population of highland and lowland dwellers by giving equal probability for each individual in selected kebeles which reflects the real prevalence of intestinal parasites in Gamo area. Furthermore, standard laboratory techniques were used; all laboratory tasks followed standard procedures; and quality control mechanisms were employed at each step of the study.

\section{Conclusion}

The high prevalence of intestinal parasitic infections among the lowland and highland dwellers in Gamo area indicated that parasitic infections are considerable public health problems. The present study has also revealed that E. histolytica/dispar and Giardia as common protozoan while A. lumberciod, hookworm and T. trichiura as common helminths that cause parasitic infection with varying magnitude in the study area. Enhancing socioeconomic status, improving sanitation facilities, instilling health education and promoting ways of keeping personal hygiene can be good strategies to control these infections in the area.

\section{Competing interests}

The authors declare that they have no competing interests. 


\section{Authors' contributions}

TW Conception of the research idea, designing, collection of data, data analysis, interpretation, and manuscript drafting. $\pi^{1}$ Designing, collection of data and manuscript reviewing. BS Collection of data and manuscript reviewing. $\Pi$ Data analysis, interpretation and manuscript drafting. All authors read and approved the final manuscript.

\section{Acknowledgments}

We duly acknowledge Arba Minch University (AMU) for the financial support for the study without which the study would have remained impracticable. We are also grateful to the support we got from Gamo Gofa Zone and the respective district administrators when we were approaching the study participants. Our special thanks go to Mr. Tesfaye Habtemariam for his language edition and Mr. Akber Chuffo for his constrictive suggestions that helped us to finalize the research in time. We also appreciate the contributions of the data collectors in collecting data for the study.

\section{Author details}

'Department of Biology, Arba Minch University, P. O. Box 21, Arba Minch, Ethiopia. ${ }^{2} \mathrm{PhD}$ candidate in Tropical and Infectious Diseases, Aklilu Lemma Institute of Pathobiology, Addis Ababa University, Addis Ababa, Ethiopia. ${ }^{3}$ Department of Medical Laboratory Science, Arba Minch University, P. O. Box 21, Arba Minch, Ethiopia. ${ }^{4}$ School of Biomedical and Laboratory Sciences, University of Gondar, P. O. Box 196, Gondar, Ethiopia.

Received: 24 November 2012 Accepted: 14 February 2013 Published: 18 February 2013

\section{References}

1. World Health Organization (WHO): Control of tropical diseases. Geneva: WHO; 1998.

2. Evans AC, Stephenson LS: Not by drugs alone: the fight against parasitic helminths. World Health Forum 1995, 16:258-261.

3. Actor JK, Shirai M, Kullberg MC, Buller RML, Sher A, Berzofsky JA: Helminth infection results in decreased virus-specific CD8+ cytotoxic T-cell and TH1 cytokine responses as well as delayed virus clearance. Proc Natl Acad Sci USA 1993, 90:948-952.

4. Bentwich Z, Kalinkovich A, Weisman Z: Immune activation is a dominant factor in pathogenesis of African AIDS. Immunol Today 1995, 16:187-191.

5. Diniz LM, Zandonade E, Dietze R, Pereira FEL, Rodrigues RR: Do intestinal nematodes increase the risk for multibacillary leprosy? AmJTrop Med Hyg 2001, 65:852-854

6. Nacher M, Singhasivanov P, Gay F, Phumratanaprapin W, Silachamroon U, Looareesuwan S: Association of helminth infection with decreased reticulocyte counts and hemoglobin concentration in Thai falciparum malaria. AmJTrop Med Hyg 2001, 65:335-337.

7. Mahfouz AAR, El-Morshedy H, Farghaly A, Khalil A: Ecological determinants of intestinal parasitic infections among pre-school children in an Urban Squatter Settlement of Egypt. J Trop Pediatric 1997, 43:341-344.

8. Phiri K, Whitty CJ, Graham SM, Ssembatya-Lule G: Urban/rural distance in prevalence of intestinal helminths in southern Malawi. Ann Top Med parasite 2000, 94:381-387.

9. Kloos H: Human behavior, health education and schistosomiasis control: a review. Soc Sci Med 1995, 40:1497-1511.

10. Pearce N: Traditional epidemiology, modern epidemiology and public health. Am J Public Health 1996, 86:678-683.

11. Teka GA: Human wastes disposal in Addis Ababa: Planning and programming Bureau. Ethiopia: Ministry of Health; 1984.

12. World Health Organization (WHO): Prevention and control of intestinal parasitic infections, WHO Technical Report Series 749. Geneva: WHO; 1987.

13. Kloos H, Tesfayohannes TM: Intestinal parasitism. In Ecology of Health and Disease in Ethiopia, Volume 3. 2nd edition. Edited by Kloos H, Zein AZ. Oxford: West View Press; 1993:223-235.

14. Ministry of Health: Comprehensive health service directory. Ethiopia: Ministry of Health; 1996.

15. Tesfa-Yohannes TM, Kloos H: Intestinal parasitism. In Ecology of Health and Disease in Ethiopia, Volume 2. 2nd edition. Edited by Zein AZ, Kloos H. Addis Ababa: Ministry of Health; 1988:214-230.

16. Jemaneh L: Comparative prevalence of some common intestinal helminth infections in different altitudinal regions in Ethiopia. Ethiop Med J 1998, 36(1):1-8
17. Haile G, Jirra C, Mola T: Intestinal parasitism among Jiren elementary and junior secondary school students, southwest Ethiopia. Ethiop J Health Dev 1994, 8:37-41.

18. Woldemichael T, Endeshaw T, Shibre T, Gebre T, Gebre T, Haddis M, Tilahun $D$, Gebreyesus L, Dereje S: Intestinal parasitic infections in western Abaya with special reference to schistosomiasis mansoni in Ethiopia. Ethiop $\mathrm{J}$ Health Dev 1999, 13(1):21-24.

19. Mengistu A, Gebre-Selassie S, Kassa T: Prevalence of intestinal parasitic infections among urban dwellers in southwest Ethiopia. Ethiop J Health Dev 2007, 21(1):12-17.

20. Ritchie LS: An ether sedimentation technique for routine stool examination. Bull US Army Med Dept 1948, 8:326-329.

21. Yeneneh $\mathrm{H}$ : Survey of intestinal parasites in Bure area, Illubabor southwest Ethiopia. Ethiop J Health Dev 1994, 8:29-35.

22. Legesse $M$, Erko B: Prevalence of intestinal parasites among schoo children in a rural area close to the southeast of lake Langano, Ethiopia. Ethiop J Health Dev 2004, 18:116-120.

23. Al-Shammari S, Khoja T, El-Khwasky F, Gad A: Intestinal parasitic diseases in Riyadh, Saudi Arabia: prevalence, socio-demographic and environmental associates. Trop Med Int Health 2001, 6:184-189.

24. McConnel E, Armstrong JC: Intestinal parasitism in fifty communities on the central plateau of Ethiopia. Ethiop Med J 1976, 14:159-169.

25. Birrie H, Eriko B: Giardiasis in Ethiopia. Ethiop J Health Dev 1995, 9(1):77-80.

26. Shaw PK, Brodsky RE, Lyman DO, Wood BT, Hibler CP, Healy GR, et al: A community wide outbreak of giardiasis with evidence of transmission by a municipal water supply. Ann Intern Med 1977, 87:426-432.

27. De Regnier DP, Cole L, Schupp DG, Erlandsen SL: Viability of Giardia cysts suspended in lake, river, and tab water. Appl Environ Microbiol 1989, 55(5):1223-1229.

28. Hardie RM, Wall PG, Gott P, Bardhan M, Bartlett CLR: Infectious diarrhea tourists staying in a resort hotel. Emerg Infect Dis 1999, 5(1):168-171.

29. Tedla S, Ayele T: Ascariasis distribution in Ethiopia. Ethiop Med J 1986, 24:79-86.

30. Tanaka H: Strongyloides infection. In Tropical Medicine and Parasitology. Edited by Goldsmith R, Heyneman D. East Norwalk: Appleton and Lange; 1989:368-373.

31. Topcu A, Ugurlu K: Distribution of intestinal parasites that in children in primary schools in Nigde and its surrounding according to age, sex and socio-economic status. Acta Parasitologica Turcica 1999, 23:286-290.

doi:10.1186/1471-2458-13-151

Cite this article as: Wegayehu et al:: Prevalence of intestinal parasitic infections among highland and lowland dwellers in Gamo area, South Ethiopia. BMC Public Health 2013 13:151.

\section{Submit your next manuscript to BioMed Central and take full advantage of:}

- Convenient online submission

- Thorough peer review

- No space constraints or color figure charges

- Immediate publication on acceptance

- Inclusion in PubMed, CAS, Scopus and Google Scholar

- Research which is freely available for redistribution

Submit your manuscript at www.biomedcentral.com/submit
C Biomed Central 